\title{
Beberapa Benda Purbakala Berprasasti Pendek Temuan Dari Wonoboyo
}

\section{Riboet Darmosoetopo}

Keywords: gold, inscription, artifact, Hindu-Buddha, silver

\section{How to Cite:}

Darmosoetopo, R. Beberapa Benda Purbakala Berprasasti Pendek Temuan Dari Wonoboyo. Berkala Arkeologi, 13(3), 37-46. https://doi.org/10.30883/jba.v13i3.615

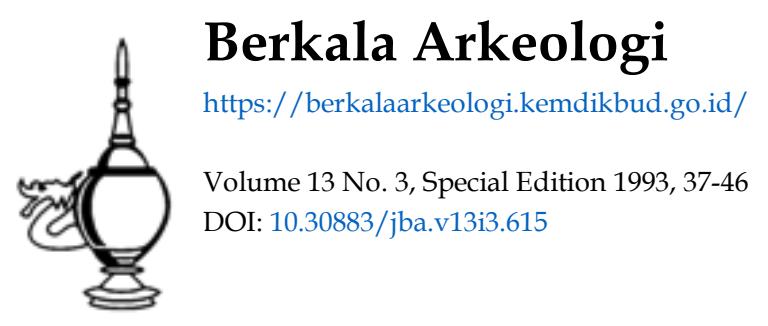

\section{(c) (i) (2)(2)}

This work is licensed under a Creative Commons Attribution-NonCommercial-ShareAlike 4.0 International License. 


\title{
beberapa benda purbakala berprasasti pendek TEMUAN DARI WONOBOYO
}

\author{
Olen: \\ Riboet Darmosoetopo
}

Di dusun Cucukan ( termasuk Desa Wonoboyo, kec. Jogonalan, Kab. Klaten) sebanyak tiga kali ditemukan benda purbakala, dari bahan emas dan perak. Beberap benda temuan ltu ada yang berprasasti pendek digoreskan pada dinding ațau alas benda.

Temuan pertama terjadi pada bulan Oktober 1990. Benda-benda yang ditemukan berupa benda perkakas (upacara?), benda pertiasan dan mata uang. Berat keseluruhan benda dari emas ada $12,436,800$ gram. Sedang berat keseluruhan barang dari perak $3.343,700$ gram. Adapun benda-benda yang berprasasti pendeḱ adalah sebagai berikut.

\section{Perkakas dan mata uang berprasasti:}

\begin{tabular}{|c|c|c|c|}
\hline No. & Jenis Benda & Prasasti & Borat (gram) \\
\hline 1 & Mangkok & tatur brat su $14 \mathrm{me} 15$ sē 3 & 585,000 \\
\hline 2 & Piring berhias & $k \bar{Q} 1$ & 750,000 \\
\hline 3 & Mangkok kecil & da brat su 4 ma 15 & 196,500 \\
\hline 4 & Mangkok kecil & Grí & \\
\hline 5 & Mangkok & $\operatorname{lin} / w a n$ & 195,500 \\
\hline 6 & Mangkok & saragl dyah buina & 237,100 \\
\hline 7 & Mangkok & crit spi & \\
\hline 8 & Mangkok & suwä & 818,800 \\
\hline 9 & Mangkok & $\begin{array}{l}\text { rajakahang lubwani(la) tań } \\
\text { ga waja }\end{array}$ & \\
\hline 10 & Mangkok & Gariawala & 177,200 \\
\hline 11 & Copuk & su $4 \mathrm{ma} 13 \mathrm{ku} 13$ & 83.000 \\
\hline 12 & Sendok & suพล̄ & 243,900 \\
\hline 13 & Gayung & brat su $8 \mathrm{ma} / 3 \mathrm{ku} 2$ & 600,000 \\
\hline 14 & Piring & brat su $15 \mathrm{ma} 1 \mathrm{ku} 1$ & \\
\hline 15 & Cincin & eri & \\
\hline 16 & $\begin{array}{l}\text { Mata uang (ada } 9 \\
\text { buah) }\end{array}$ & tā (aksara Dowanagarl) & 2,400 \\
\hline
\end{tabular}


Perkakas dan mata uang perak berprasastt:

\begin{tabular}{|c|c|c|c|}
\hline No. & Jenis Benda & Prasast & Berat (gram) \\
\hline $\begin{array}{l}1 . \\
2 .\end{array}$ & $\begin{array}{l}\text { Mangkok } \\
\text { Mata uang }\end{array}$ & $\begin{array}{l}\text { tImca } \\
m \overline{\bar{Q}} \text { (aksara Dewanagarl) }\end{array}$ & \\
\hline
\end{tabular}

Temuan kedua terjadl pada Bulan Nopember 1990 berupa mata uang emas. Jumlah seluruhnya ada 6.387 (enam ribu tiga ratus delapan puluh tujuh) butir, berat seluruhnya ada $15,576 \mathrm{~kg}$. Ukuran masing-masing mata uang rata-rata $6 \times 5 \times 4,2 \mathrm{~mm}$ dengan goresan aksara tâ. (Dewanagari pada sisi depannya, sedang sisi belakang digoresi seperti bunga.

Temuan ketiga terjadi pada Bulan Desember 1990 berupa benda perhiasan antara lain mahkota, ikat pinggang. Ikat pinggang ini berupa potongan-potongan yang disambung pada ujung dan pangkalnya. Sebagian ada yang sudah teriepas. Setiap potongan di ujung dan pangkalmya ada tanda (aksara, angka, kode) sebagai berikut:

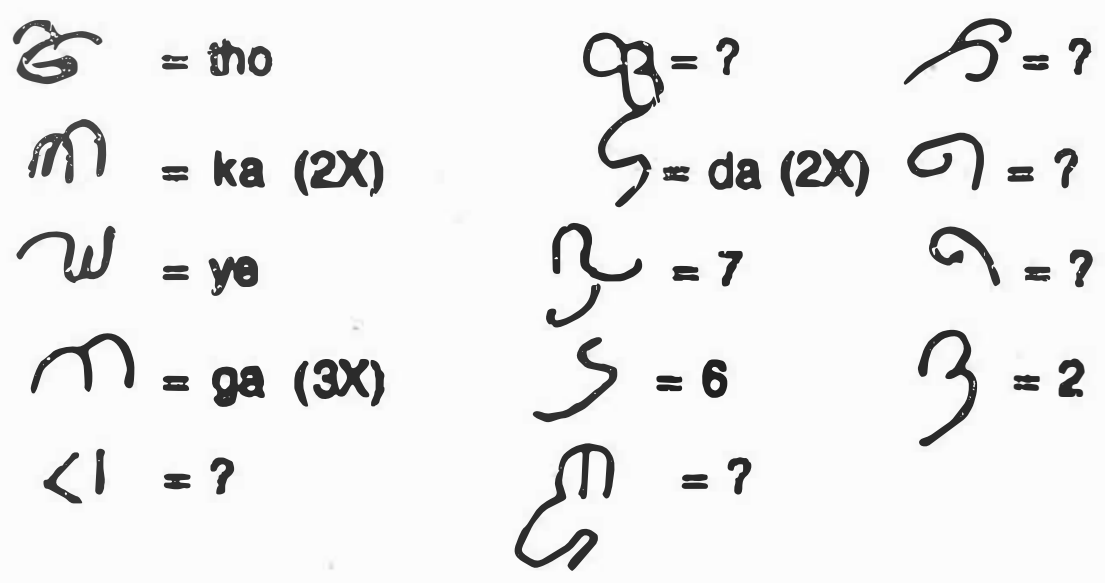

Sampal sekarang masin banyak masalah yang belum dapat dipecankan secara tuntas. Masalah-masalah itu antar lain mengapa benda-benda itu terpusat dl satu tempat yang beradlus sekltar 25 meter ?. Benda-benda litu millk slapa dan beresal darl abad berapa?. Mengingat prasastl-prasastl yang ada padanya adalah prasastl pendek dan tidak da data yang tongkap yang dapat disamakan dengan data yang terdapat pada prasasti-prasastl panjang yang sudah olketahul 
dengan pasti, maka Jawaban terhadap masalah yang dlajukan masih belum me-mueskan. Dari segi prasasti memang ada beberapa takta penting yang perlu dlanallsis leblh lanjut. Dari anallsis prasastlprasasti pendek InI dlharapkan akan menjawab alternatif.

Mangkok emas berat 237,100 gram (hasll penlmbangan) terdapat tullsan saragl dyah buña. Kata saragl blasanya dikaltkan dengan kata opak. maoöng dan inuman ...saragl opak 1 saragl magöng 1 saragl inuman 1 ... (Wukajana: 10). Pada prasatl Wukajana frasa itu dikaitkan dengan sajlan untuk Sang Hyang Brahma. Saragl dapat diartikan saiuan kelompok misalnya seperangkat alat minum, satu stel pakalan dst. la frasa saragi dyah buna yang dlgoreskan pada sebuah mangkok dapat diartikan seperangkat wadah yang berupa mangkok (mengirgaî ditemukan beberapa buah mangkok) milik dyah Buna. Dyah adalah artikel untuk nama (garchanama) seorang bangsawan, seperit halnya artikel pu. Mengingat hal itu maka dapat diperkirakan dyah Buna adalah seorang bangsawaan.

Mangkok emas dengan tulisan $\varepsilon \bar{i}$ SDl. Kata çri biasanya sebagai artikel sebutan maharaja menjadi cri mähäraja Kecuall itu

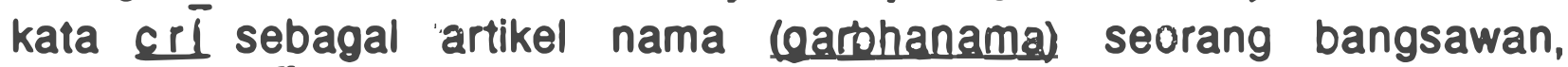
misalnya Çrì Bhāru (Tajl 823), Çrī Spi.(Er Kuwing \pm 837), Çrī Wawa (Kinwu 849). Oleh karena ltu Crī Spl sepertl Dyah Buna adalah seorang bangsawan. Apakah ada hubungan antara Dyan̆ Buna dengan Çrl Spl ? mengingat benda-benda ditemukan dalam satu konsentrasl tentunya ada hubungan keluarga antara mereka.

Apakah dyah Buna dan Cri Spl dapat dlanggap sebagal pembuat benda-benda liu dan akhirnya namanya dlgoreskan pada benda ciptaannya sepertl penulls prasastl mencantumkan namanya di akhlr kallmat ?. Pendapat demiklan perlu disangsikan mengingat profesi pande emas termasuk profesinya orang cāndala.

Kalinganya/kang sinanggah candala ring loka/ lima kwehnya/ noyan ta / surasut ng.a.ranya wwang amahat/ krm/dahangaranya wwang amalantnl pranaghana ngaranya wwang an-jagall kumbhaka-raka ngaranya wwang andyunl dhatudagdha ngaranya wwang apande ma-s/ lka ta.n yogya paranana umahnya dening wwang m.enak / yawat ta nan.d. a-lanil Ing sang hyang hafl (Slokantara 43 ) 
Apablla mereka hanya seorang pande tentunya tldak akan berani memakal artikel dyah dan cei untuk nama mereka. Dikatakan seorang bangsawan tida mau datang di rumah seorang candāla takut kalau menjadi (kelularan) candạala (n̄andalanl). Apalagi nama seorang candāla digoreskan pada benda (upacara?) milik seorang bangsawan, tentu tidak akan terjadi. Demikian juga blla frasa itu ditafsirkan benda millk dyah Buña dan Çri Spl yang akan dipersembahkan kepada raja, kiranya perlu dipertimbangkan. Justru kiranya dapat ditafsirkan benda-benda Itu sebagal wadah persembahan kepada pujaan mereka.

Kusen telah mencoba membandingkan dan mencari kesejajaran nama-nama desa yang disebut oleh prasasti dengan nama-nama desa yang sekarang ada di daerah Prambanan dan sekitarnya. Kusen berkesimpulan bahwa sampai sekarang masih ada unsur-unsur nama desa dahulu yang tersimpan pada desa-desa masa sekarang (Kusen 1991). Menurut struktur jaman dulu, pembagian wilayah terdirl dari keraton dengan kotanya, desa dan dusun. Sedang struktur pemerintahannya khususnya periode abad VIII - X AD seorang raja dibantu oleh beberapa rakryān dan pamagat yang sering disebut rakryān kagnåo. Mereka terdiri dari rakryān hlne rakryān halu. Lakryan slrikan, pamgat bawang dan rakryān wka. Nama-nama mereka memakai artikel dyah dan pu. Mereka tidak mændapat gajih, tetapl mendapat tanah lungguh, biasanya disebut watak. Jadl daerah watak hine atau watak halu artinya daerah lungguh dari cakryän hino dan rakryãn halu. Seorang pemegang lungguh bukan kepala pemerintahan di daerah lungguhnya, seibab kepala pemerintahan desa adalah para tāma. Pemegang lungguh agaknya sebagal sesepuh atau pengayom di daerah lungguhnya. la berhak menerima pajak dari daerah lungguhnya. Karena pemegang lungguh sebagal pengavem di daerah lungguhnya, ia juga mendapat persembahan dari penduduk. Bahkan pemegang lungguh juga mempunyai dharma di tanah lungguhnya. Oleh karena litu tentunya ada upacara-upacara khusus yang dliakukan di tanah lungguh. Kiranya tidak berleblhan blla dikatakan bahwa pemegang lungguh merupakan wakll raja dan menjadl raja "kecil" daerah lungguhnya. Dyah Buna dan Cri Spl dapat dlasosiasikan demiklan. Mereka adalah pemegang lungguh dl desa-desa sektiar tempat penemuan benda-benda purbakata Wonoboyo. Hanya nama lungguh (watak)nya tldak diketahul, sebab nama dlambll darl 
nama pangkat atau Jabatan misalnya watak hino. watak halu watak wka Penafsiran demlklan didukung oleh penemuan fondasi-fondasi bangunan hasll penggallan.

Petunjuk yang dapat dlpergunakan untuk menentukan umur temuan benda purbakala darl Wonoboyo hanya berupa aksara (paleografl) dan rellef Ramayana. Namun demlklan masih menemul kesulltan. Dillhat darl segl paleografl, aksara-aksara dlgoreskan pada beberapa wadah termasuk aksara standar, yaltu aksara yang dlpergunakan antara raja PIkatan sampal dengan Balltung (JG de Casparis). Cerltera Ramayana dlsebut dalam prasastl Wukajana.

... hlnyunakan tontonan mamidu sang tangkll hyang sinalu macarita bhima kumara manglgal kicaka sl faluk macarlta rāmãyana ...(Wukajana, B: 9-10).

Prasastl Wukajana dikeluarkan oleh raja Balltung: Jadl ceritera Ramayana terkenal pada masa raja Balitung. WF Stutterheim menghubungkan candl Prambanan dengan raja Balitung. Sedang JG de Casparis mengatakan bahwa candl Prambanan darl masa raja PIkatan. Jadl balk dari paleografi maupun data relief menunjukkan bahna benda-benda ltu berasal darl masa antara raja Pikatan sampal dengan raja Balltung. Dari raja PIkatan (768 C) sampai raja Balltung (827) cukup lama yaltu 59 tahun. Selama 59 tahun ada raja-raja sebagal berlkut: Rakal PIkatan Dyah Saladu (768 -777 C), Rakal Kayuwangl Dyah Lokapala (777 - 806 C), Dyah Tagawas (806-807 C), Rakal Panumbangan Dyah Dewendra (807-808 C). Rakai Gurunwangl dyah Bhadra (808-816 C. Rakal Wangkal Humalang (816-820 C), Rakal Watukura dyah Balitung (827 C -..... ) (Wanua Tńan III 830 C). JadI balk darl data paleogrnfl maupun data relief belum dapat menentukan umur benda-benda temuan dl Wonoboyo secara pastl.

Sampal sekarang pun belum dapat memastlkan bahwa bendabenda itu sejak dahulu berada di situ. Tidak menutup kemungkinan dulu benda-benda ltu berada dl sebelah utara darl tempat temuan sekarang. Karena terlanggar lahar benda-benda litu terbawa ke arah selatan sampai dl tempat temuan sekarang. Dugaan demlklan didasarkan pada:

a. Sampal sekarang belum pernah ditemukan benda sertaan yang tldak dalam wadah.

b. Blla benda-benda liu maslh di tempat semula, tentunya berada 
di dalam lingkungan fondasi bangunan.

c. Daerah tempat temuan dan sekitarnya adalah tempat aliran lahar.

d Penggalian di tempat temuan tidak menghasllkan sesuatu barang maupun fondasi bangunan.

Pemblcaraan yang bersifat alternasi-spekulatlf seperti disebut dl atas, diakhir sejauh itu dulu. Selanjutnya akan diblcarakan tentang satuan berat untuk emas dan perak beserta perbandingannya. Satuan berat untuk emas lalah kāll suwarna mása, kupang dan hatak atau

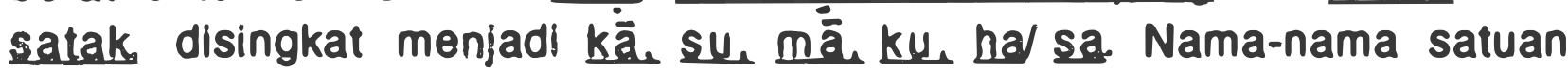
demikian adalah rangkuman darl beberapa prasastl:

$\begin{array}{lllll}\text { Prasasti Bulai } & \text { mas kā } 2 & \text { su } 7 \text { mā } 8 \\ \text { Prasasti Dang Nawi } & \text { mas } & & \text { su } 16 \text { mā } 10 \text { ku } 2 \text { ha } 5 \\ \text { Prasasti Kamalagyan } & \text { mas } & \text { su } 17 \text { mā } 14 \text { ku } 4 \text { sā } 4 \\ \text { Prasasti Kwak } & \text { mas kā } 1 \text { su } 11 \text { má } 4 \text { ku } 3\end{array}$

Darl kutlpan-kutipan nama satuannya dapat di susun sebagal berikut:

mas ka ... su .... ma... ku... ha/sa...

Prasasti-prasastl pendek dari Wonoboyo jelas bahwa ka .. su ma ku ha/sa tukan menyatakan nilalnya, melainkan menyatakan beratnya: tatur bratsu 14 mā 15 sả 3 artinya emas berat 14 su 15 ma 3 sa. WF. Stutterheim dalam penelitiannya berkisimpulan:

$$
\begin{array}{ll}
1 \mathrm{su} & =38,601 \mathrm{gram} \\
1 \mathrm{ma} & =2,414 \mathrm{gram} \\
1 \mathrm{ku} & =0,603 \mathrm{gram}
\end{array}
$$

Selanjutnya dikatakan bahwa:

$$
\begin{aligned}
& 1 \mathrm{mā} \quad=1 / 6 \mathrm{su} \\
& 1 \mathrm{tá} \quad=1 / 16 \mathrm{kā} \\
& 1 \mathrm{su}=16 \mathrm{ma}=64 \mathrm{ku} \text { (W.F. Stutterhelm, 1940: 17,31). }
\end{aligned}
$$


Masalah yang ekan diajukan ialah apakah berat satuan benda-benda dari Wonoboyo sama dengan yang diajukan oleh WF. Stutterheim ?.

Dalam hal mencari berat satuan dan perbandingannya, tidak semua prasasti pendek dari Wonoboyo dapat dipergunakan. Hanya ada empat prasasti yang dapai dianallsis lebih lanjut yaitu prasasti pada mangkok (no.l), prasastl pada piring (no.2), prasasti pada mangkok kecll (no.3) dan prasastl pada piring (no.14). Sedang prasastl pada cepuk berat su $4 \mathrm{ma} 13 \mathrm{ku}$ 13; (no.II) tentunya bersama tutupnya. Pada hal iutupnya belum diketahul. Demikian pula prasasti pada gayung berat su $8 \mathrm{ma} 13 \mathrm{ku} 2$ (no.13) tentunya bersama dengan tangkainya. Tangkainya juga belum diketahui. Oleh karena itu prasasti pada cepuk dan prasasti pada gayung tidak dilkutkan dalam analisis. Keempat prasasti yang dianalisis lebih Jauh ialah:

1. Mangkok kecil

: bratsu 4 mä 15 : 196,500 gram

2. Piring

3. Piring berhias

: braisu 15mä1 ku 1 : 600,000 gram

4. Mangkok

: kā 1

: 750,000 gram

:laturbratsu 14 mā15 sā 3585,000 gram

Dldapat hasil analisls sebagal berikut:

\begin{tabular}{|l|c|c|c|c|c|}
\hline \multirow{2}{*}{$\begin{array}{l}\text { Berat rata-rata } \\
\text { prasasti } \\
\text { Wonoboyo }\end{array}$} & $\mathrm{ka}$ & su & $\mathrm{ma}$ & $\mathrm{ku}$ & hassá \\
\cline { 2 - 6 } & 751.963 & 39.5777 & 2,4735 & 0,6184 & 0,1035 \\
\hline Stutterhelm & - & 38,601 & 2,414 & 0,603 & - \\
\hline
\end{tabular}

$\begin{aligned} \text { Jadl : } 1 \mathrm{kā} & =19 \mathrm{su} \\ 1 \mathrm{su} & =16 \mathrm{ma} \\ 1 \mathrm{má} & =4 \mathrm{ku} \\ 1 \mathrm{ku} & =6 \mathrm{sá}\end{aligned}$

Temuan prasastl yang menyatakan berat untuk perak dari 
Wonoboyo hanya terdapat pada mata uang yaitu dengan nama satuan ma singkatan dari masa. Adapun urutan nama satuan berat perak adalah ka tha ma singkatan darl katl charana dan masa. Stutterheim dalam penelltiannya berkesimpulan:

$$
\begin{array}{ll}
1 \text { katl } & =617,610 \text { gram } \\
1 \text { dharana } & =38,601 \text { gram } \\
1 \text { masa } & =2,412 \text { gram }
\end{array}
$$

Selanjutnya dikatakan bahwa:

$$
\begin{array}{ll}
1 \mathrm{ka} & =16 \mathrm{dha} \\
1 \mathrm{dha} & =16 \mathrm{ma}
\end{array}
$$

Buchari mengatakan:

$$
1 \text { kati = } 32 \text { dharana }
$$

Jones mengatakan:

$$
1 \text { kati }=40 \text { dha rana }
$$

Prasasti Rumbiga II $827 \mathrm{C}$ :

$$
1 \text { dharana }=16 \text { masa }
$$

Agar mudah dingat, dimasukan dalam bagan sebagal berikut:

\begin{tabular}{|l|r|c|l|}
\hline & ka & dha & ma \\
\hline & & Gram & \\
\hline Stutterheim & 617,61 & 38,601 & 2,41 \\
\cline { 2 - 4 } & & Perbandingan & \\
\hline & 1 & 16 & 256 \\
\hline $\begin{array}{l}\text { Buchar } \\
\text { Jones } \\
\text { Pras. Rumblga II }\end{array}$ & 1 & 32 & - \\
\hline
\end{tabular}




\section{PENUTUR}

1. Benda-benda termuan dart Wonoboyo (kecuall mata uang) merupakan barang upacara balk upacara pemujaan kepada Dewa maupun upecara kebesaran pemegang lungguh.

2. Latar belakang keagamaan pemillk benda-benda itu adalah Clwaistls.

3. Dapat dl tafslikan benda-benda ltu millk pemegang lungguh ("raja kecli') bernama Dyaṇ Buña dan crī Spl.

4. Benda-benda itu berasal darl antara tahun 268 sampal dengan masa raja Balitung.

5. Beberapa prasastl yang menyatakan berat benda, dapat dipergunakan untuk mencarl berat setlap satuan masa lalu dan perbandinganya berat setiap satuan masa sekarang. 


\section{KEPU8TARAAN}

Casparls, JG. de. 1975. Indoneslan Paleography. Koln, J Brll.

Darmosoetopo, fiboet . 1990. Laporan Ponomuan Benda-bonda Purbakala di Ds. Wonoboyo, Kec. Jogonalan, Kab. Klaten, 1990.

- 1991. Prasastl-prasastl Pendek dari Wonoboyo Bahan Diskusi di Kab. Klaten, 5 Sept. 1991

Jones, AMB. Early Tenth Century Java from the Inscriptions. A Study of Economic, Social and Administrative Condition in the First Quarter of the Century. Holland Cinnaminson - USA 1984 (Dis)

Kusen. 1991. Identfilkasi Toponim dalam Prasasti Jawa Kuna abad IX-X dari Prambanan dan Sekitamya dengan Toponim Masa KInl. Rapat Analisis Sumber Tertulis Masa Klasik Trawulan 18 - 23 Nop.1991.

Sharada, Rani. 1957. Slokāntara, An Old Javanese Didactlc Text. International Academic of Indian Culture.

Stutterheim, WF. 1940. Oorkonde van Balltung ult 905 AD (Randusari 1). INI 1940: 3.29 